\author{
Military Technical College \\ Kobry El-Kobbah, \\ Cairo, Egypt.
}

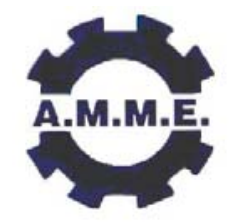
$13^{\text {th }}$ International Conference on Applied Mechanics and Mechanical Engineering.

\title{
ACOUSTIC AND THERMAL PROPERTIES OF POLYMERIC AND BUILDING MATERIALS
}

\author{
FOJTU $^{\star} D$. and LAPCIK ${ }^{\star *} \mathrm{~L}$. Jr.
}

\begin{abstract}
Discordant sound annoys, awakens, angers, distracts, frustrates and creates stresses that result in physiological and psychological problems. It is invisible, yet its effects are clearly evident, and it pervades every facet of life.
\end{abstract}

Synthetic polymers and building materials play an important role in construction of buildings mainly as a surface furnishing components.

That is why in this paper we present results of our experiments focused on characterization of the basic acoustic material performance parameters, e.g. frequency dependence of the sound absorption coefficient of the articles prepared from expanded poly(styrene), poly(propylene), poly(vinyl chloride), mineral wool and plasterboard.

Paper was focused on determination of the acoustic properties (in the frequency range $16-6400 \mathrm{~Hz}$ ) of selected synthetic polymer materials such as expanded poly(styrene), poly(propylene), poly(vinyl chloride), mineral wool and plasterboard. Values of sound absorption coefficient for frequency range were measured.

Second part of article forms measurements of thermal properties with non-stationary conditions, e.g. thermal conductivity evaluated from dependence of temperature and time by mathematical model with using Gauss-Newton method.

Obtained results allow optimization of the wall structure construction for household and building industry applications. It's possible to prepare and produce new materials, optionally combinations of existing materials, to improvement damping and vibrating properties.

\section{KEY WORDS}

acoustics, sound absorption coefficient, frequency dependence, interior materials, thermal conductivity, non-stationary heat conduction

\footnotetext{
* Graduate student, Inst. of Physics and Material Engineering. Faculty of Technology, Tomas Bata University in Zlin, Zlin, Czech Republic.

** Professor, Inst. of Physics and Material Engineering. Faculty of Technology, Tomas Bata University in Zlin, Zlin, Czech Republic.
} 


\section{INTRODUCTION}

At the present time, increased demand for application of synthetic polymers in automotive industry and aeronautics is evident, mainly in utilization of polypropylene (PP), polycarbonate (PC), expanded polystyrene (EPS), mineral wool or plasterboards components of the interior, exterior or the functional parts of buildings. Polymers were able to replace more traditional engineering materials, such as metals on account of their many desirable physical and chemical properties (e.g. high strength-to-weight ratio, resistance to corrosion etc.) and their relatively low price [1]. With today's growing focus on noise control issues and the emergence of sound quality as an important aspect of product design, acoustic material testing is becoming increasingly relevant to engineers, designers and manufacturers from a broad range of industries. Acoustic material testing is the process by which the acoustic characteristics of materials are determined in terms of absorption, reflection, impedance, and admittance. There are many different methods to determine the acoustic properties of materials. They mainly involve exposing them to known sound fields and measuring the effect on the sound field caused by their presence. There is a range of standards covering material testing (e.g., ISO 10534-2, ASTM E 1050-98), prescribing well-defined acoustical conditions and special instrumentation to ensure accuracy and repeatability. Due to the increased demand for higher safety, comfort and tougher regulatory legislation valid for the general aviation, both of the crew and the passengers, the acoustic exposure during take off, flight and landing must be minimized. For that reason, in this paper results of our measurements of the sound absorption coefficient of selected synthetic polymer based materials (poly(styrene), poly(propylene) and poly(vinyl chloride)) are presented. Building materials (mineral wool and plasterboard are presented too.

\section{THEORY}

The sound absorption coefficient $\alpha$ is defined by the ratio of the absorbed acoustic output $P_{2}$ and the general incident acoustic output $P_{1}$ :

$$
\alpha=\frac{P_{2}}{P_{1}}
$$

In case the wall reflects incidence acoustic wave totally sound absorption coefficient is $\alpha=0$. If all incidence energy is absorbed then $\alpha=1$.

Thermal conductivity $\lambda$ is the property of a material that indicates its ability to conduct heat. It's amount of heat in W, which transfer with steady stage through measured plate

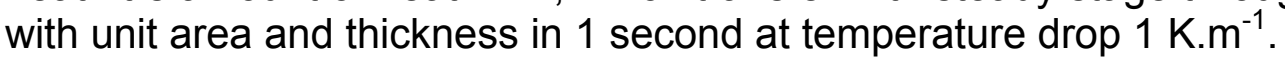

$$
\lambda=\frac{Q}{F \cdot \tau} \cdot \frac{d \delta}{d t}
$$

\section{EXPERIMENTAL}

\section{Samples}

Following materials were selected for the acoustic experiments: expanded poly(styrene) (thickness $7 \mathrm{~mm}$ and $30 \mathrm{~mm}$ ) (FATRA Napajedla), poly(vinyl chloride) (thickness $3 \mathrm{~mm}$ ) 
(FATRA Napajedla), poly(propylene) (thickness $1.6 \mathrm{~mm}$ ) (FATRA Napajedla), Mineral wool (Rotaflex super TP03040) (thickness $40 \mathrm{~mm}$ ) and plasterboard (thickness $10 \mathrm{~mm}$ ). For the acoustic measurements 10 samples of each tested material were prepared of the circular shape of 30 resp. $100 \mathrm{~mm}$ diameter.

For the thermal measurements 10 samples of each tested material were prepared of the circular shape of $90 \mathrm{~mm}$ diameter.

\section{Determination of the sound absorption coefficient}

The sound absorption coefficient measurements were performed on two-channel signal analyser Brüel \& Kjæer type 2034 and PULSE analyser Brüel \& Kjaer type 3560-B-030 equipped with Kundt's tube in the frequency range of $16 \mathrm{~Hz}$ to $6400 \mathrm{~Hz}$. All measurements were performed according to the Czech Standards ČSN 73 0513, which is in compliance with the ISO norms.

\section{Determination of the thermal conductivity coefficient}

The thermal conductivity coefficient measurements were performed on Fitch's instrument with non-stationary method. Measured data were evaluated with non-linear regression (Gauss-Newton method).

\section{RESULTS AND DISCUSSION}

For the evaluation of the acoustic damping properties of the tested materials the frequency dependency of the sound absorption coefficient was taken in the range of 100 to $6300 \mathrm{~Hz}$. From the dependencies shown in the Figures 1 one can detect sound absorption maximum of 0.846 at the frequency $6300 \mathrm{~Hz}$ for poly(vinyl chloride) sample, while the first sound absorption occurred at $2550 \mathrm{~Hz}(\alpha=0.44)$. The mean value $\alpha=$ 0.273 was found for the frequency range $1250-5000 \mathrm{~Hz}$. Results for the expanded poly(styrene) of the $7 \mathrm{~mm}$ thickness are shown in Figure 2. The highest value of the sound absorption coefficient $\alpha=0.29$ was found to be at the frequency $6300 \mathrm{~Hz}$. The mean value $\alpha=0.112$ was found for the frequency range $1250-5000 \mathrm{~Hz}$. The effect of the sample thickness on the complex acoustic impedance was followed by the measurement of the two different thick samples (expanded poly(styrene)). The second sample under study was one of the $30 \mathrm{~mm}$ thickness. Obtained results were of $\alpha=0.37$ (at $6300 \mathrm{~Hz}$ ), mean value $\alpha=0.177(1250-5000 \mathrm{~Hz})$. In the case of poly(propylene) mean value of $\alpha=0.179$ (in the frequency range of $1000-5000 \mathrm{~Hz}$ ), maximum value of $\alpha=0.613$ at the frequency $6300 \mathrm{~Hz}$ (see Figure 4).

From the dependencies shown in the Figures 5 one can detect sound absorption maximum of 0.86 at the frequency $2500 \mathrm{~Hz}$ for mineral wool sample. The mean value $\alpha$ $=0.715$ was found for the frequency range $1000-5000 \mathrm{~Hz}$. Results for the plasterboard of the $10 \mathrm{~mm}$ thickness are shown in Figure 6 . The highest value of the sound absorption coefficient $\alpha=0.42$ was found to be at the frequency $2500 \mathrm{~Hz}$. The mean value $\alpha=0.24$ was found for the frequency range $1000-5000 \mathrm{~Hz}$. 


\section{CONCLUSION}

This paper was focused on determination of the acoustic properties (in the frequency range $16-6400 \mathrm{~Hz}$ ) of selected synthetic polymer materials such as expanded poly(styrene), poly(propylene), poly(vinyl chloride) and building materials (mineral wool and plasterboard). Values of sound absorption coefficient for frequency range were measured.

Mineral wool was evaluated as material with the best acoustic properties from the series of the tested materials.

Poly(vinyl chloride) and plasterboard were found to be the second best material of the studied series, having slightly worse acoustic properties in comparison to the mineral wool. It was found, that this material is not offering high enough sound damping characteristics, but its thermal insulating properties as found in our previous studies seems to be interesting from the practical point of view.

Poly(vinyl chloride) is a potential applicant for the production of flooring covering and other covering layers, where elimination of the structure-borne sound and unwanted vibrations is very needed. At the present time, this material is used for production of the plastic windows.

Material poly(propylene) and expanded poly(styrene) embodies the most worst acoustic properties, therefore is used mainly for aesthetic and decorative purposes.

On base of analysis of thermal properties of selected materials may be submited, that the best thermal-insulating material is mineral wool, second best is material polystyrene. Plasterboard isn't good thermal-insulating material. This material is very used in building industry due to mechanical properties. It's used as cover layer of the another materials.

\section{ACKNOWLEDGEMENT}

Authors would like to express their gratitude for financing of this research by Ministry of Education, Youth and Physical Training of the Czech Republic (Grant No. VZ MSM7088352101).

\section{REFERENCES}

[1] LAPCIKOVA, B. - LAPCIK, L. - SMOLKA, P. - DLABAJA, R. - HUI, D.: Application of Radio Frequency Glow Discharge Plasma for Enhancing Adhesion Bonds in Polymer/Polymer Joints, J. Appl. Polym. Sci. 102 No. 2 (2006), p. 1827-1833.

[2] JULINA J.: "Akustické vlastnosti vybraných stavebních materiálư", Bakalářská práce, FT UTB ZLÍN, 88 STR., 2007.

[3] GRULICH O.: „Využití numerických metod při analýze tlumících parametrů materiálu.

[4] KULHÁNEK F. : Stavební fyzika II. Stavební tepelná technika, ČVUT Praha 2006.

[5] VAVERKA J.,CHYBÍK J.,MRLÍK F.: Stavební fyzika 2. Stavební tepelná technika, VUTIUM, Brno 2000. 


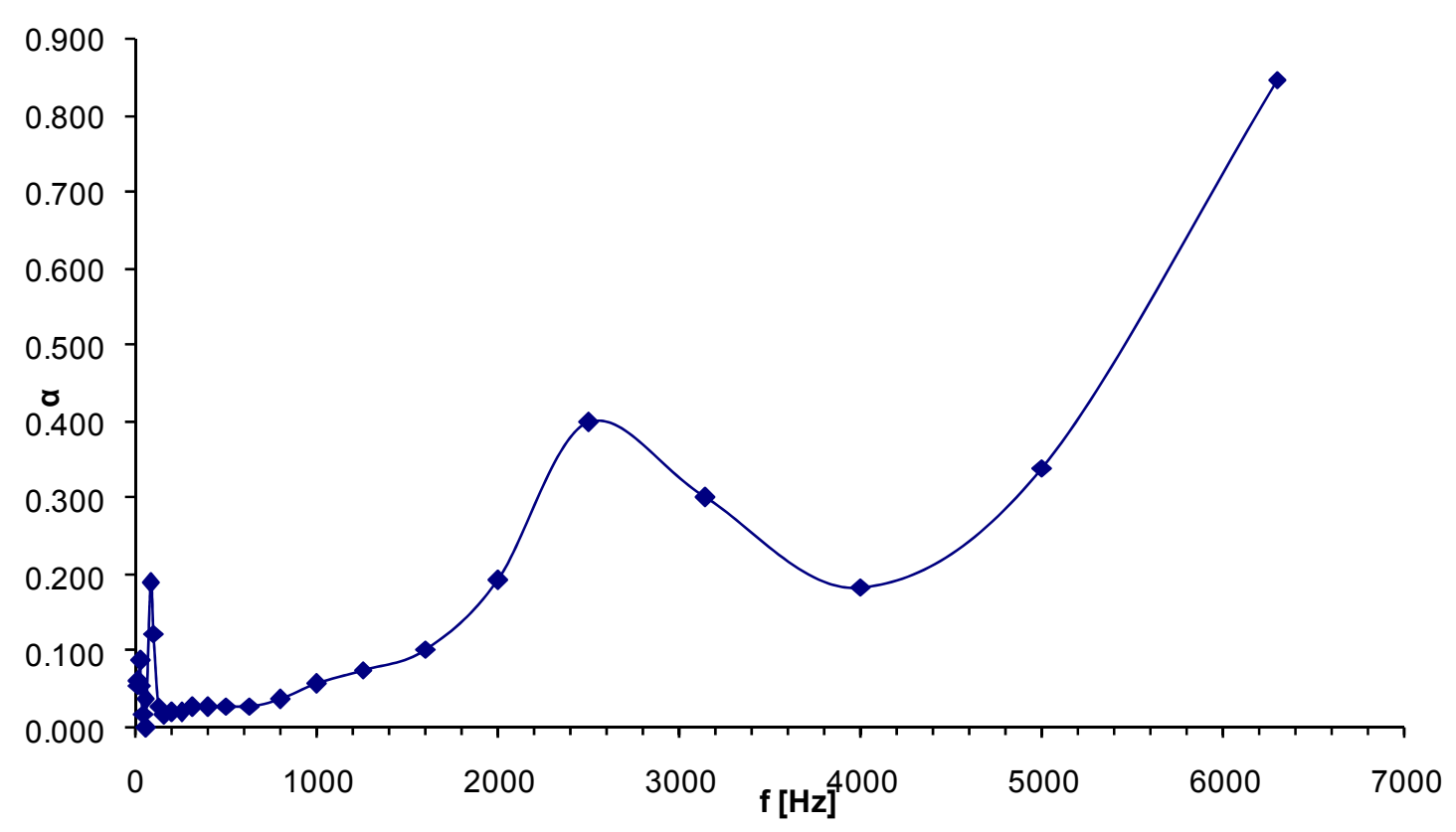

Figure 1. Frequency dependence of the sound absorption coefficient of poly(vinyl chloride), sample thickness $3 \mathrm{~mm}$.

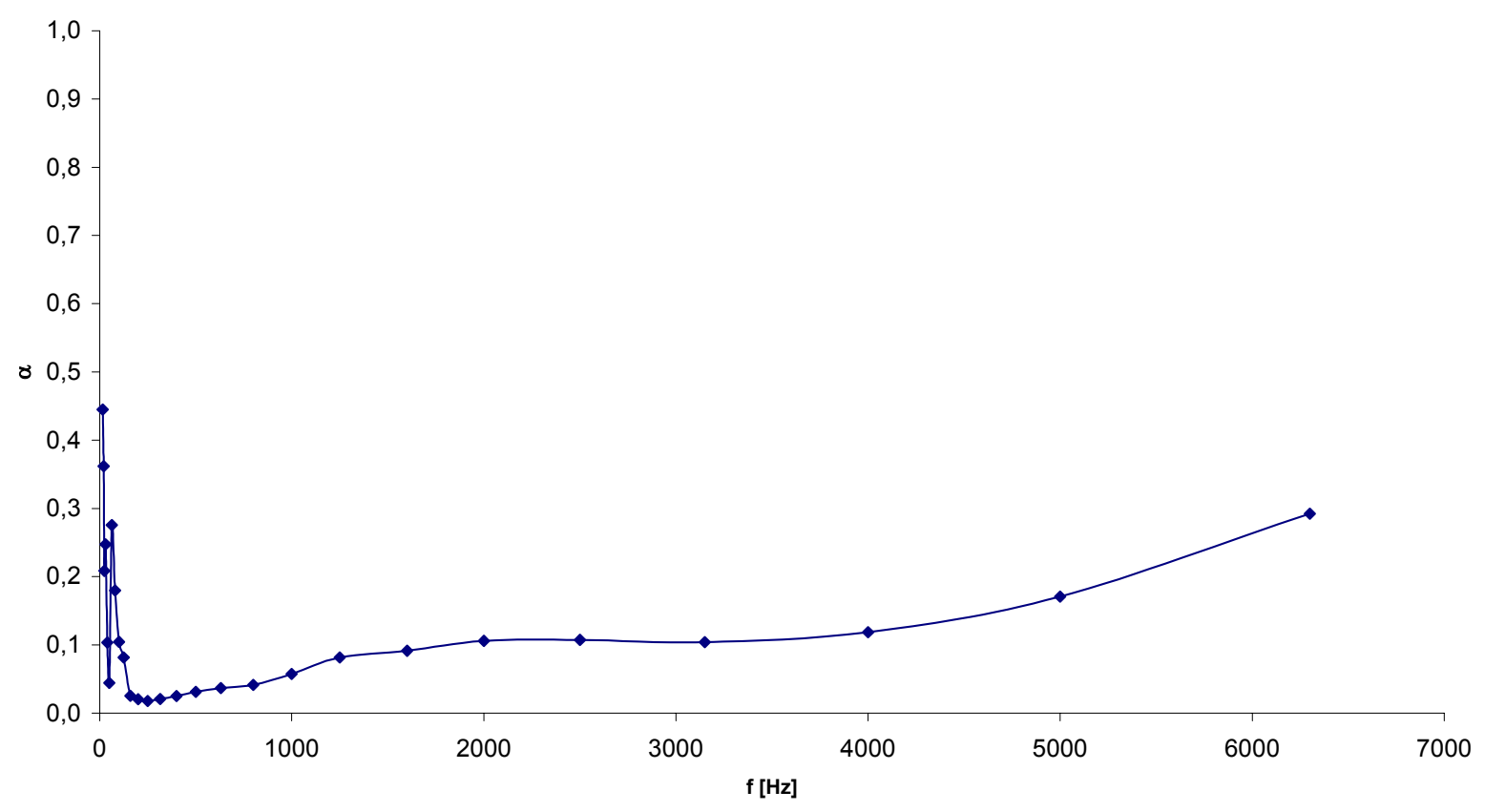

Figure 2. Frequency dependence of the sound absorption coefficient of expanded poly(styrene), sample thickness $7 \mathrm{~mm}$. 


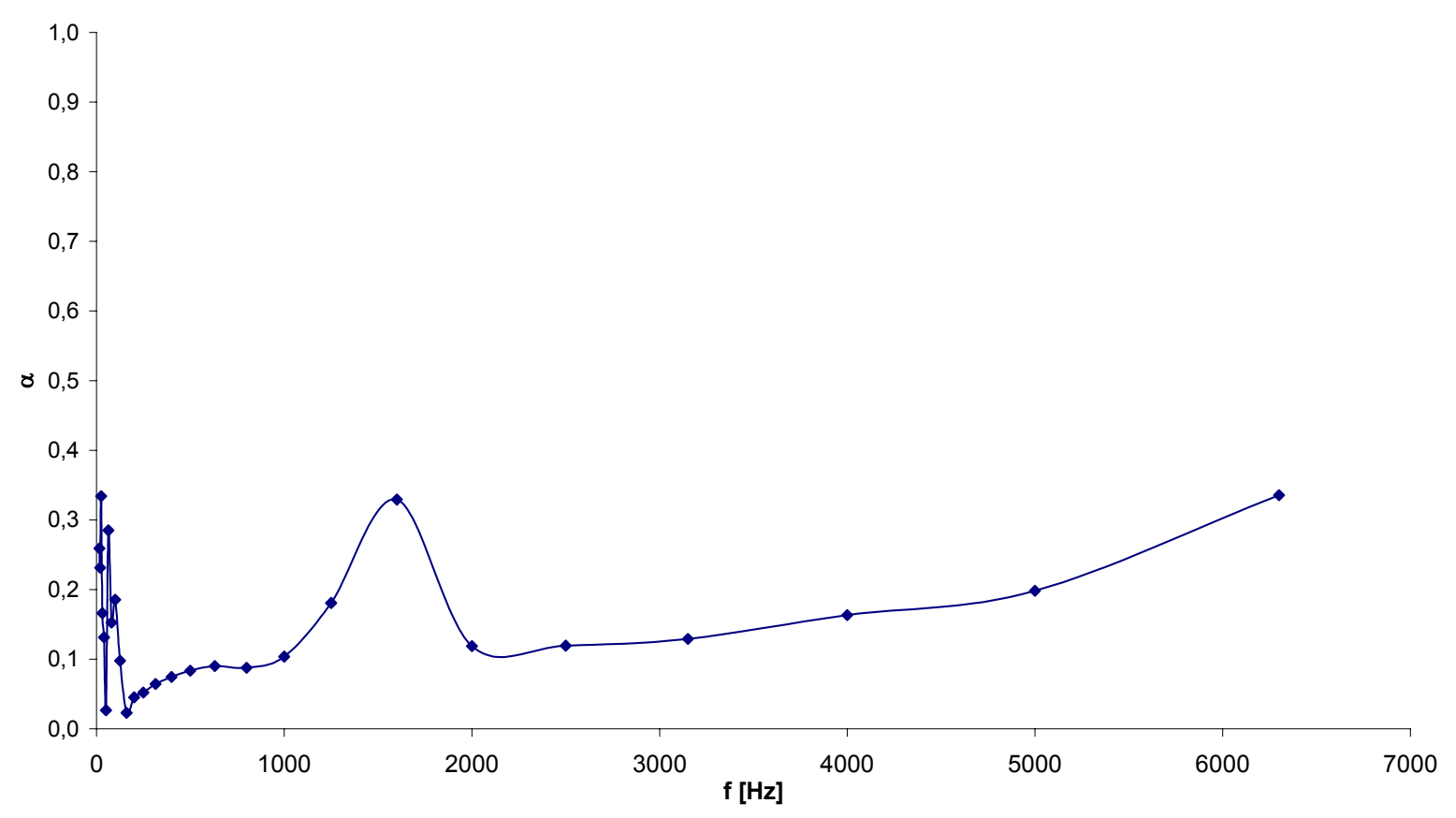

Figure 3. Frequency dependence of the sound absorption coefficient of expanded poly(styrene), sample thickness $30 \mathrm{~mm}$.

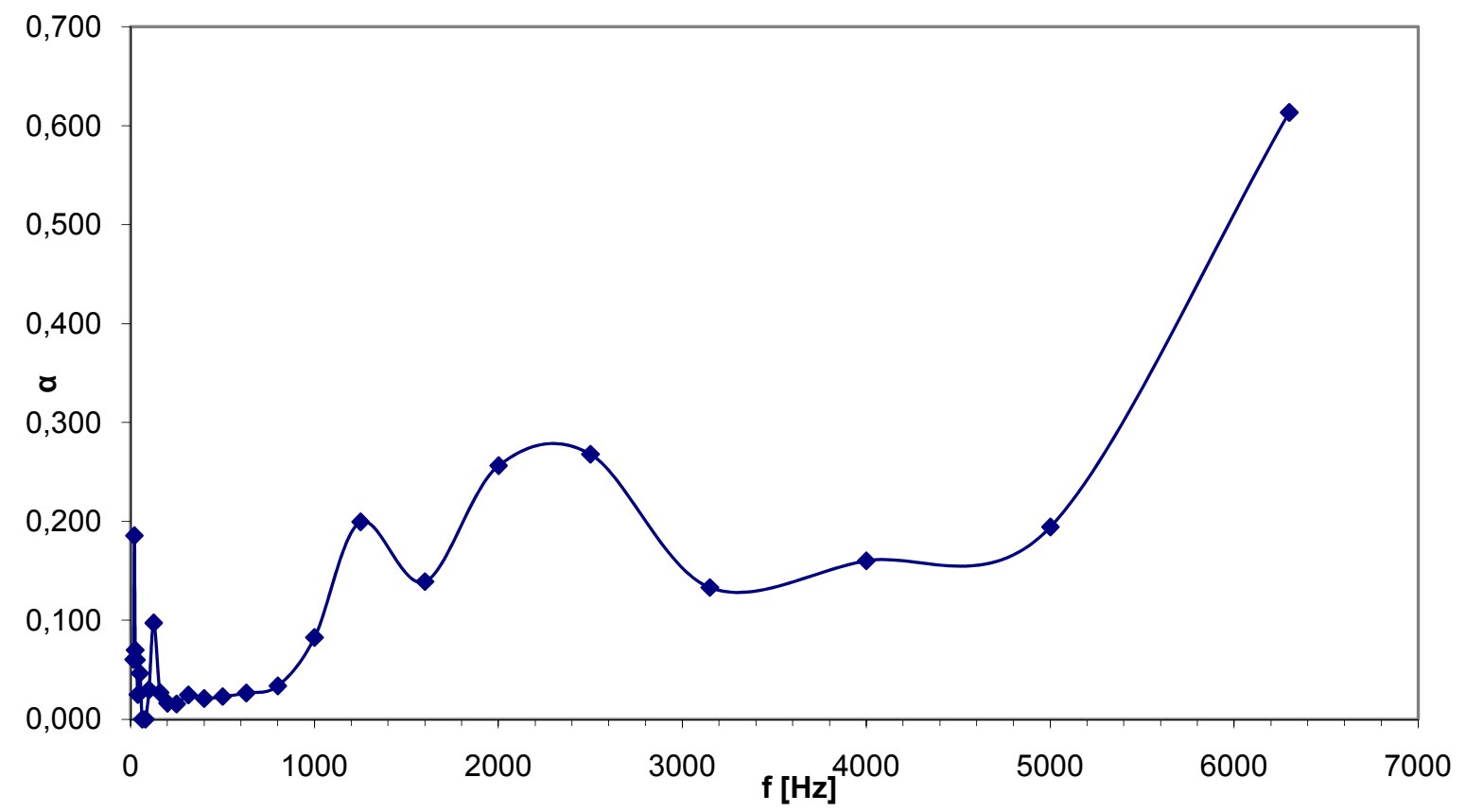

Figure 4. Frequency dependence of the sound absorption coefficient of polypropylene, sample thickness $1,6 \mathrm{~mm}$. 


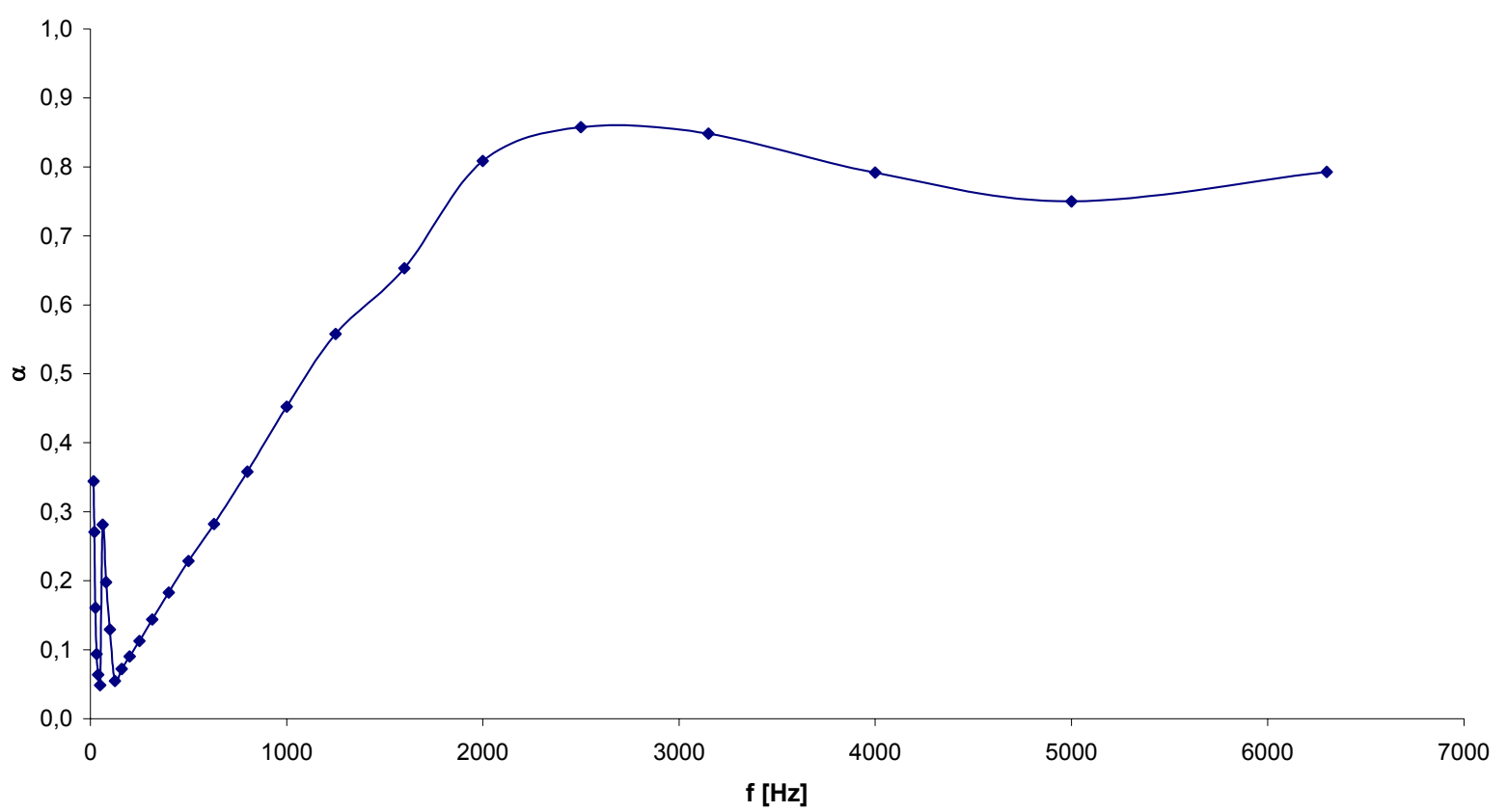

Figure 5. Frequency dependence of the sound absorption coefficient of mineral wool, sample thickness $40 \mathrm{~mm}$.

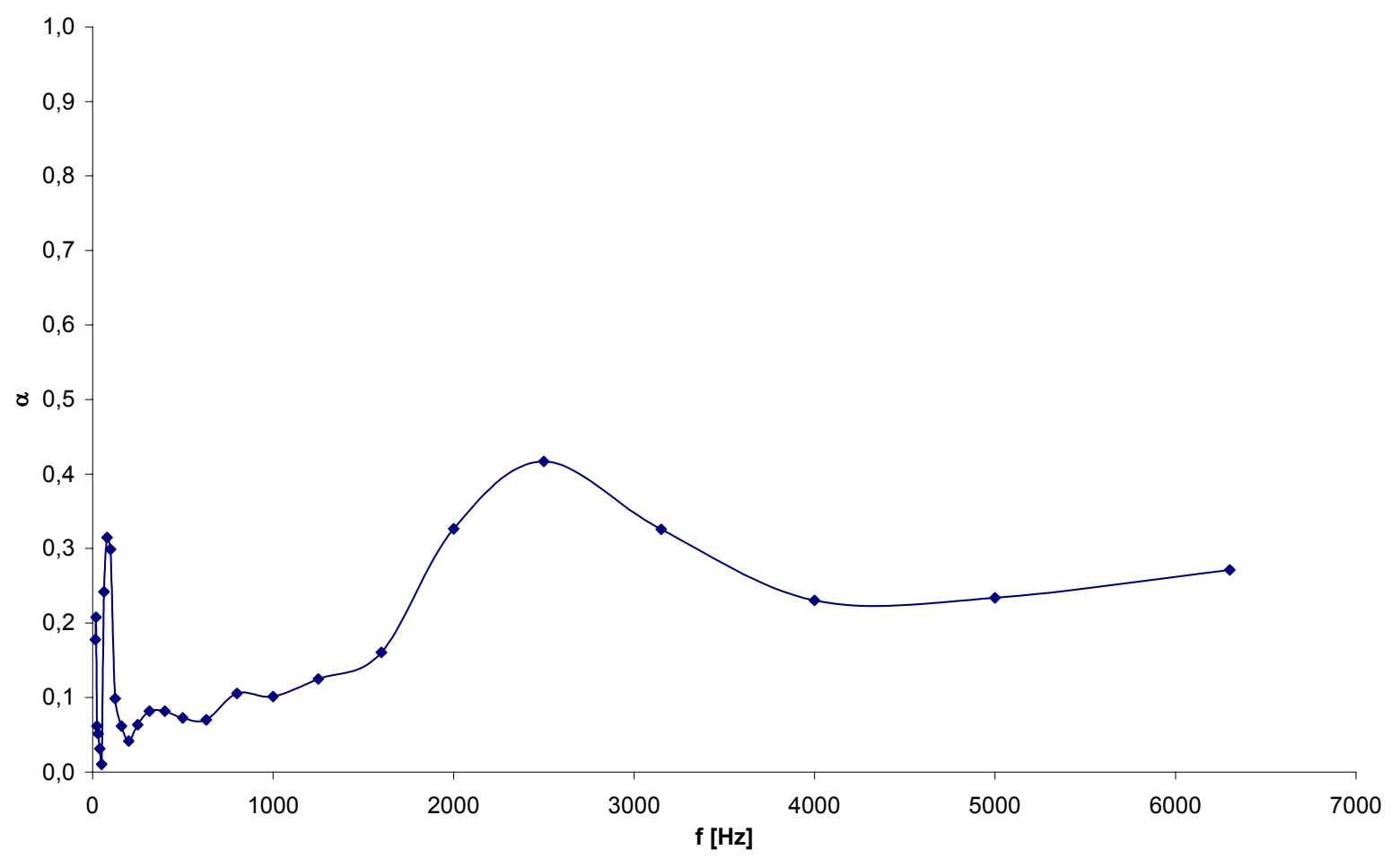

Figure 6. Frequency dependence of the sound absorption coefficient of plasterboard, sample thickness $10 \mathrm{~mm}$. 
Table 1. Thermal conductivity of selected materials

Material

Mineral wool Expanded polystyren

Plasterboard

Polypropylen $(1,6 \mathrm{~mm})$

Polyvinylchlorid $(3 \mathrm{~mm})$
Thermal Conductivity

$$
\begin{gathered}
\stackrel{\lambda}{\left(W \cdot m^{-1} \cdot K^{-1}\right)} \\
0,01036 \\
0,02249 \\
0,12979 \\
0,09278 \\
0,08624
\end{gathered}
$$

